\title{
Correction to: Endocrinology and Metabolism
}

Sai-Ching Jim Yeung

\section{Correction to: Chapter 29 in: K. H. Todd et al. (eds.), Oncologic Emergency Medicine,} https://doi.org/10.1007/978-3-030-67123-5_29

Figure 29.3 had three typographical errors in the figure label in the original publication of the book. This has been replaced by a corrected version of Figure 29.3. 
C2

S.-C. J. Young

Hypermagnesemia
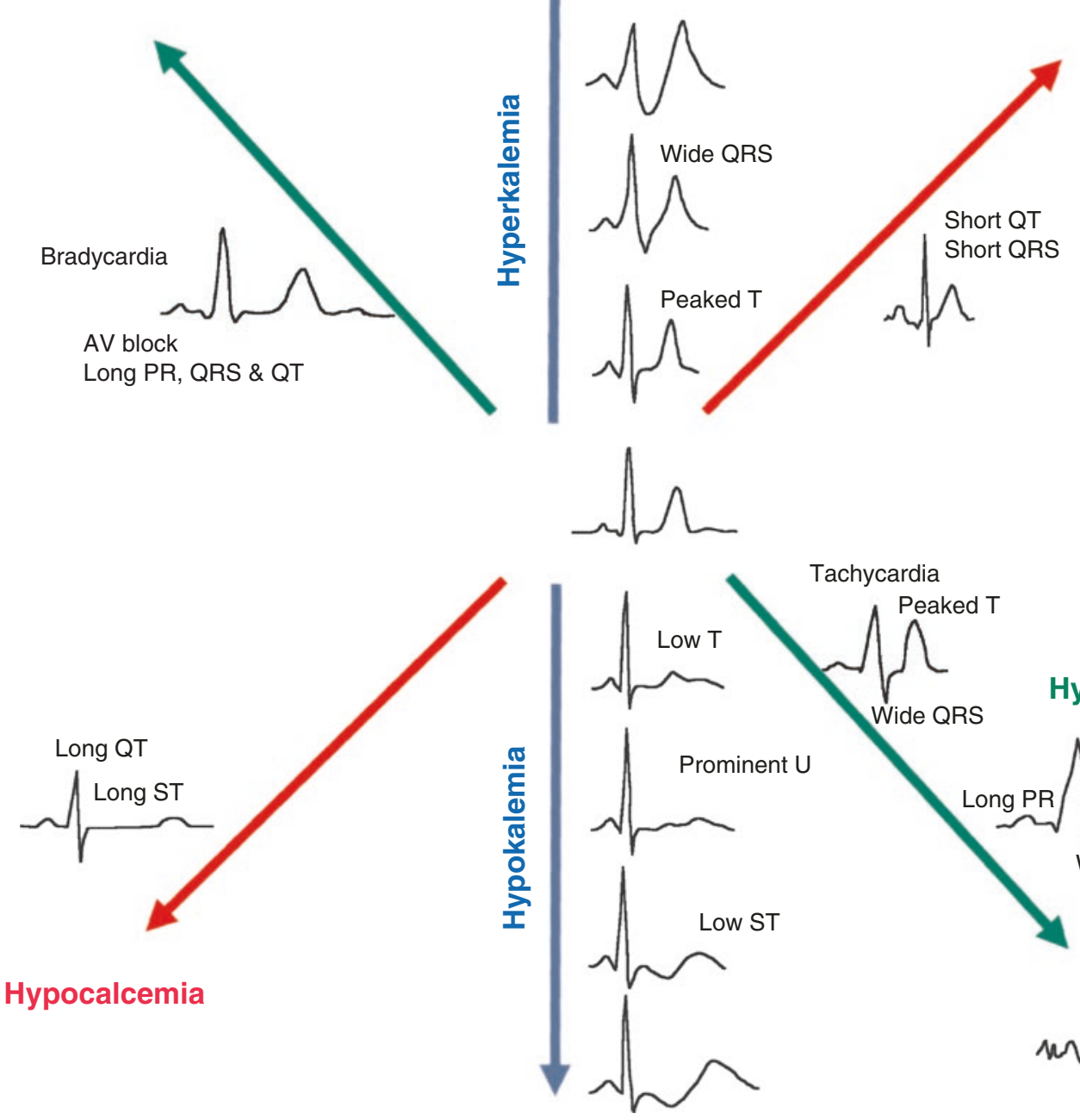

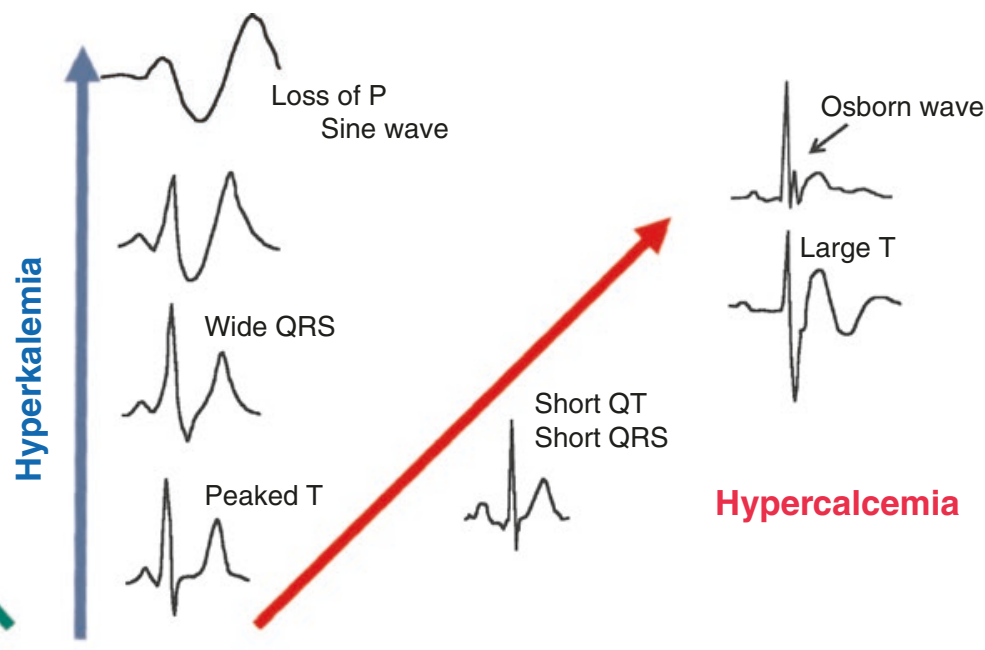

Tachycardia

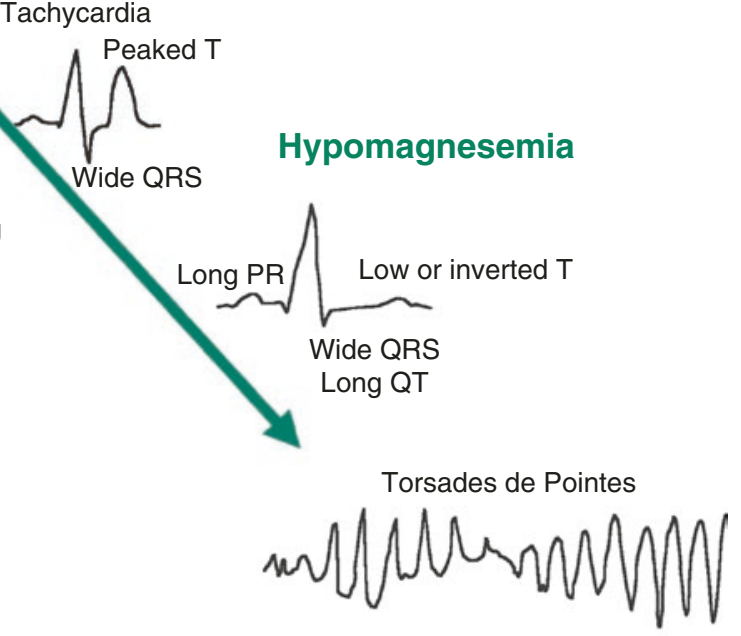

Fig. 29.3 EKG changes in the presence of electrolyte abnormalities 